\title{
MORPHOLOGICAL CLASSIFICATION OF RAT CORTICAL NEURONS IN CELL CULTURE ${ }^{1}$
}

\author{
ARNOLD R. KRIEGSTEIN² AND MARC A. DICHTER \\ Department of Neurology and Neuroscience, Children's Hospital Medical Center, Boston, Massachusetts 02115
}

Received January 5, 1983; Revised March 15, 1983; Accepted March 17, 1983

\begin{abstract}
Neurons in "mature" (4- to 6-week-old) dissociated cell cultures of 15-day gestational age rat fetal cortex were injected with Lucifer Yellow in order to compare their detailed morphological features with those of cortical neurons in situ, and in order to determine which features of cellular morphology were dependent on local environmental conditions. Neurons were characterized by their cell form (pyramidal, multipolar, fusiform, etc.), dendritic branching pattern, spine density, and axonal projections. The neurons in culture appeared to display all the morphological features seen in cortical neurons in situ. These characteristics appeared to be independent of whether an individual neuron grew in a dense or sparse region of the culture. In addition, examination of neurons during early differentiation indicated that many of their morphological features developed as soon as the neurons could be recognized and before extensive synapse formation occurred.
\end{abstract}

Neurons from central and peripheral vertebrate nervous systems can be identified by a variety of morphological, biochemical, histochemical, electrophysiological, pharmacological, and functional characteristics, some of which depend on their locations and some of which are genetically determined properties of the neurons themselves. Although ultimately all of a neuron's properties have a genetic basis, the contribution of the environment to the differentiation of individual vertebrate neurons is not well understood. In a cell culture preparation, neuroblasts and undifferentiated neurons are removed from their natural environments and allowed to differentiate in a two-dimensional system under controlled conditions. Since neurons in cell culture have been shown to develop a variety of morphological, biochemical, and electrophysiological characteristics comparable to their counterparts in situ, we can examine how these properties depend on specific culture conditions and how the different properties interrelate with one another in individual neurons.

It has already been demonstrated that several neuronal cell types which have distinct morphological features in vivo exhibit those features in the relatively artificial environment of dissociated cell culture. These in-

\footnotetext{
${ }^{1}$ We gratefully acknowledge the technical assistance of Bernard Biales and Sara Vasquez and the comments of Drs. K. L. Chow, Deb Barnes, and Matt Frosch on an earlier draft of this manuscript. This work was supported by National Institutes of Health Grant NS 15362, The Children's Hospital Mental Retardation Center Core Grant HD 06276, and a Klingenstein Fellowship in the Neurosciences to A. R. K.

${ }^{2}$ Current address: Department of Neurology, Stanford University School of Medicine, Stanford, CA 94305.
}

clude spherical sensory ganglion cells (Scott et al., 1969), large multipolar spinal cord motor neuron-like cells (Fischbach, 1970), and cortical pyramidal-shaped cells (Dichter, 1978). In addition, some specific aspects of neuron-glial relations can also be maintained in culture (Waxman et al., 1977). Whether these and other cel' types maintain their particular biochemical and physiological differentiation in vitro has not been fully ascertained, in part because such studies are hard to perform in the complex structure of the cortex in situ.

We have been interested in the development of mammalian cortical neurons, the formation of local synaptic connections between cortical neurons, and the correlation of specific morphological features of neurons with their biochemical or physiological properties. We have, thus, begun an analysis of the detailed morphology of cortical neurons in culture and the interaction between local environmental conditions and the development of certain morphological characteristics.

There have been many attempts over the years to divide cortical neurons in silu into meaningful subclasses on the basis of structural features alone. Golgi (1886) focused on axonal morphology and divided cortical neurons into two classes, cells with long axons and cells with short axons. Lorente de No (1922) considered both axonal morphology and dendritic branching and described as many as 40 subtypes based on their relationship to cortical layering (later he reduced this number to five; Lorente de No, 1938). Sholl (1953) proposed a classification scheme that again reduced the subtypes to two classes, pyramidal and nonpyramidal or stellate, a dis- 
tinction that has been preserved in almost all subsequent classification schemes. However, the Golgi-Cox stain Sholl employed was relatively insensitive to dendritic features such as spines. Many subsequent studies employed the rapid Golgi method which stains spines well. These authors have emphasized the importance of spine density in classifying neurons (Globus and Scheibel, 1967c; Lund, 1973; Garey, 1971; West and Kemper, 1976; Feldman and Peters, 1978; Peters and Regidor, 1982). For example, Feldman and Peters (1978) classified nonpyramidal cells, based on their dendritic branching pattern, into three groups described as multipolar, bipolar, and bitufted and further subdivided these groups on the basis of their dendritic spine density into spinous, sparsely spinous, and spine-free varieties. The pattern of axon branching has also played a role in some classification schemes. A study by Jones (1975) divided nonpyramidal cell types in monkey somatosensory cortex into seven groups, each with a unique pattern of axonal ramification. The subcortical gray matter has also been the subject of similar attempts at cell classification (see for example Cajal, 1911; Sekuler et al., 1975; Difiglia et al., 1976).

We have injected Lucifer Yellow into cortical neurons grown in a dissociated cell culture system in order to study neuronal morphologies. We wanted to determine whether the morphological criteria that had previously been applied to cortical neurons in vivo could be applied to neurons in vitro. Cultured cells were studied in terms of their overall shape, dendritic branching patterns, dendritic spine density, and axonal morphology. In addition, each of these parameters was examined in relation to local conditions of neuronal density within the cultures.

\section{Materials and Methods}

Intracellular micropipettes were made from fiber-filled glass (Frederick Haer) pulled on a model P77 (BrownFlaming micropipette puller (Sutter Instrument Co., San Francisco, CA). The electrodes were back-filled with $3 \%$ aqueous Lucifer Yellow CH, supplied by Walter Stewart, and had resistances of 100 to 150 megohms.

The electrodes were beveled to resistances of 80 to 100 megohms by immersion into a 50-ml beaker containing a slurry of 120-grid silicon carbide (Buehler Limited, Evanston, IL) spun by a magnetic stirring rod. The electrodes were connected to a high input impedance preamplifier (WPI) equipped with a modified Wheatstone bridge circuit for passing currents through the electrode. Potentials were displayed on an oscilloscope screen and were recorded with a penwriter.

In all cells studied, penetration of the cell by the microelectrode was accompanied by a DC potential shift. Membrane potentials were generally $-40 \mathrm{mV}$ or greater, and action potentials could be triggered by depolarizing current pulses in all cells. Cells were filled with dye by passing constant 3-nA hyperpolarizing current through the electrode for 3 to $5 \mathrm{~min}$. By the end of the period of dye staining, the electrophysiological properties of the cclls had deteriorated and many were no longer able to generate action potentials.

Cortical cultures were placed in a heated chamber $\left(35^{\circ} \mathrm{C}\right)$ on the stage in an inverted phase contrast micro- scope (Zeiss) equipped with an epifluorescence light source with an excitation filter of 450 to $490 \mathrm{~nm}$ and a barrier filter of $520 \mathrm{~nm}$ in the light path. Cells were first visualized under phase contrast optics $(\times 200)$ and then monitored through fluorescence filters as they were being filled with dye. Cultures containing filled cells were fixed first by dropwise addition of $4 \%$ formaldehyde in $0.1 \mathrm{M}$ sodium phosphate buffer ( $\mathrm{pH}$ 7.4) and then by immersion into the fixative for $30 \mathrm{~min}$. Some coverslips were subsequently rinsed in buffer, dehydrated in graded alcohol, and mounted in methacrylate mounting medium; others were simply rinsed in buffer and mounted in glycerol so that the cells could still be visualized under phase contrast optics. The methacrylate proved a more stable mounting medium with very little fading of fluorescence over time, whereas the glycerol-mounted tissue developed a bothersome autofluorescence after several months. The photographs were taken of fixed and mounted tissue on a Zeiss photomicroscope equipped for both epifluorescence and phase contrast microscopy.

Detailed methods for preparing and maintaining cortical cells in culture from 15-day rat embryos have been described elsewhere (Dichter, 1978; Snodgrass et al., 1980). Briefly, pregnant Sprague-Dawley rats, 15 days past conception, were stunned, and the embryos were removed using sterile technique. The cortical hemispheres were carefully removed, and the underlying diencephalon and hippocampus were trimmed away. The cortices were gently minced into small pieces, treated with trypsin at $37^{\circ} \mathrm{C}$ for $2 \mathrm{hr}$, and triturated to produced a cell suspension. The cells were filtered and plated at a concentration of $1.5 \times 10^{5}$ whole cells onto collagen- and polylysine-covered 12 -mm diameter glass coverslips. Cultures were used for neuronal staining at 2 to 6 weeks in vitro.

\section{Results}

Cell types. For 66 of the 70 cells reported here, it was possible to classify them as pyramidal-like (18 of 70 ), fusiform (21 of 70), or multipolar (27 of 70), according to the following criteria. A pyramidal-like cell had a triangular perikaryon with one prominent "apical" dendrite at its apex, several somewhat shorter "basilar" dendrites, and many spines along the dendrites (Fig. 1, $A$ and $B$ ). If the dendritic processes emerged only from opposite poles of the perikaryon, the cell was classified as fusiform, either bipolar or bitufted, depending on whether there were single or multiple dendrities, respectively. Fusiform cells often had spherical somata and had either spiny or aspinous dendrites (Fig. 1, $C$ and $D$ ). Cells were classified as multipolar if they had multiple processes of approximately equal lengths arising from multiple sites around the perikaryon. Multipolar cells had a wide range of spine densities on their dendrites (Fig. 1, $E$ and $F$ ).

Growth of different cell types. In cultured cortical neurons, indirect evidence suggests that the distinctions between pyramidal-like, fusiform, and multipolar cell types are preserved from the earliest states of differentiation. When neurons first begin to develop processes during the first $24 \mathrm{hr}$ in culture, many can be classified into one or another of the three morphological groups 

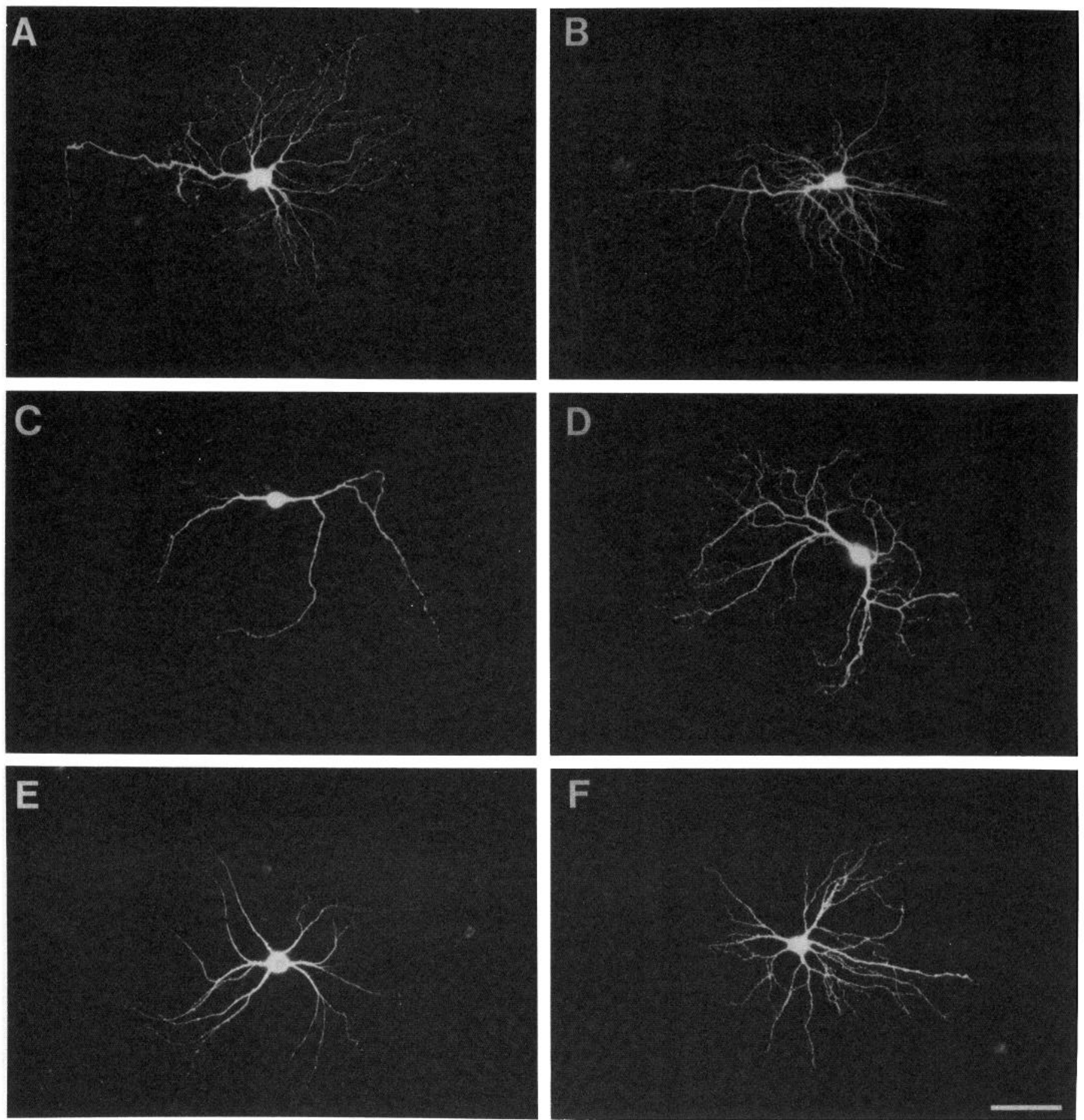

Figure 1. Mature neuron morphology. $A$ and B, Examples of two dye-filled cells that resemble pyramidal cells in morphology. They both have spiny processes, triangular perikarya, basilar dendrites, and a prominent apical dendrite. $C$, A bipolar neuron with aspinous dendrites. $D$, A fusiform cell with spiny dendrites. $E$, A sparsely spined multipolar neuron. $F$, A spiny multipolar neuron. Scale bar $=100 \mu$.

(Fig. 2). Moreover, when 15 individual cells were observed in serial photographs taken at 6 -hr intervals, cells that initially developed as fusiform, multipolar, or pyramidal-like retained these morphologies during the first week in culture. Later, individual cell processes became obscured by the overgrowing astrocyte layer, and neuronal morphology was more difficult to describe.
Dendritic branching. An assessment of dendritic branching was obtained by a modification of the concentric ring method of Sholl (1953). Photographs were taken of four cells of each neuron type, and concentric circles were drawn centered on the cell body with radii that increased by $20-\mu$ increments from 20 to $300 \mu$. The number of dendritic processes crossing each circle was 
then counted and tabulated. A graphic representation of these data is seen in Figure 3, which illustrates the degree of dendritic branching for each of four cell types, pyramidal-like, bipolar, and spinous, and aspinous multipolar neurons. The dendritic branching pattern of pyramidallike neurons is distinctly different from the pattern seen in bipolar neurons which have fewer dendritic branches but longer dendritic lengths. Spiny multipolar cells also have a more profuse dendritic arbor than aspiny multipolar cells. The mean peak number of dendritic crossings for pyramidal neurons in vitro is 28 at $80 \mu$ from the perikarya and is higher than their in situ counterparts where peak values range from 12 to 18 crossings between 55 and $100 \mu$ from the perikaryon (Sholl, 1953; Green-
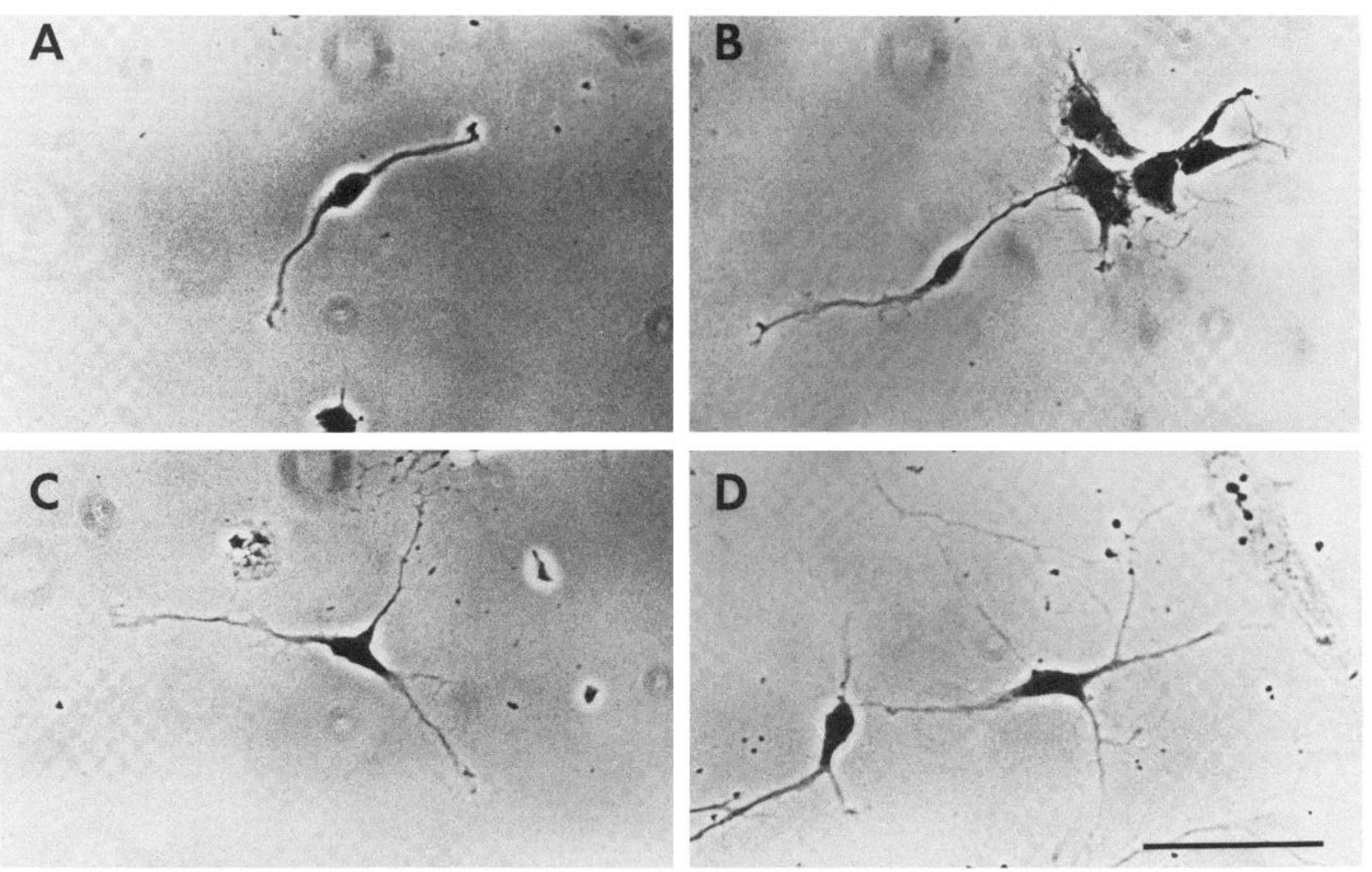

Figure 2. Development of cortical neurons in vitro. Cells were photographed in phase contrast after $24 \mathrm{hr}$ in culture. $A$ and $B$, Bipolar cells. $C$, A pyramidal-like cell. $D$, A multipolar cell on the right and a fusiform cell on the left. Scale bar $=25 \mu$.

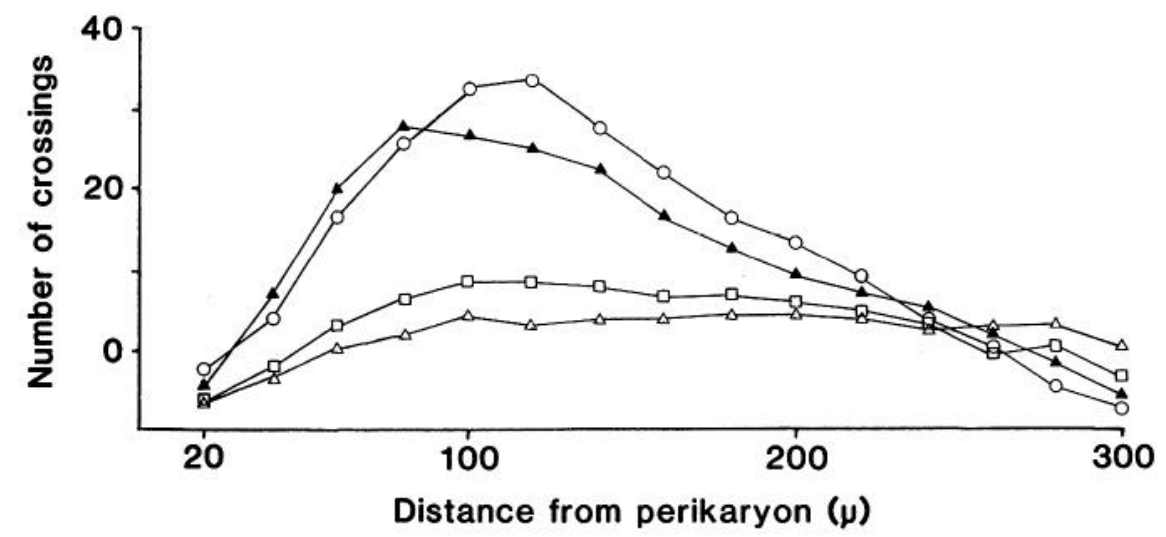

Figure 3. Dendritic branching analysis of four neuronal types based on number of processes crossing a series of concentric circles at $20-\mu$ intervals. Solid triangles, pyramidal neurons $(n=3)$. Open triangles, bipolar neurons $(n=3)$. Open circles, spiny multipolar neurons $(n=4)$. Open squares, aspinous multipolar neurons $(n=$ 4). 
ough and Volkmar, 1973; Kelche and Will, 1982). These differences may be a result of the in vitro method which compresses the three-dimensional cell processes into an essentially two-dimensional plane and would be expected to increase the number of counted crossings.

Spine density. The development of spines might be a useful morphological trait to study the way environment influences neuronal development. Cells were sorted into four categories on the basis of dendritic spine density. Aspinous cells had no spines visible per $50-\mu$ dendritic length measured on a secondary dendritic branch approximately two cell diameters from the perikaryon. Cells were classified as sparsely spiny if they had fewer than 15 spines $/ 50 \mu$, spiny if they had 15 to 25 spines $/ 50$ $\mu$, and very spiny if they had greater than 25 spines $/ 50$ $\mu$ (see Fig. $4 A$ ). All of the cells classified as pyramidallike were in the two categories of highest spine density. Although there were morphological variations in the dendritic spines and both sessile and pedunculated forms were seen, no attempt was made to categorize these differences.

In cultured cortical neurons, there was a correlation between spine density and the number of dendritic branches. In general, cells with fewer dendritic branches also had fewer spines on their dendrites. This is illus- trated in Figure 3, which shows a greater degree of dendritic branching in spiny multipolar neurons compared to nonspiny multipolar neurons. An index of dendritic branching was obtained from photographs of each cell by counting the number of processes that crossed a circle with a radius of $100 \mu$ centered on the cell perikaryon (Fig. $4 B$ ). Cells with the highest number of processes also tended to have the highest spine densities. This trend is illustrated in Figure 5 (top), where the number of spines is plotted against the degree of dendritic branching. In contrast, when spine density is graphed against age in culture from 2 to 6 weeks, no clear pattern emerges (Fig. 5, bottom).

The correlation of spines with cell type is illustrated in Figure 6. All bipolar cells examined $(n=5)$ have long dendrites with few branches and are either aspinous or sparsely spinous. In contrast, many multipolar cells and all pyramidal-type cells have multiple branching dendrites that bear many spines.

The neuronal environment does not seem to influence whether a cell will have spinous or aspinous processes in vitro. Cells were examined in relation to neighboring neurons in the microscopic field to determine whether proximity to other neurons and their processes might correlate with the number of dendritic spines. Figure 7
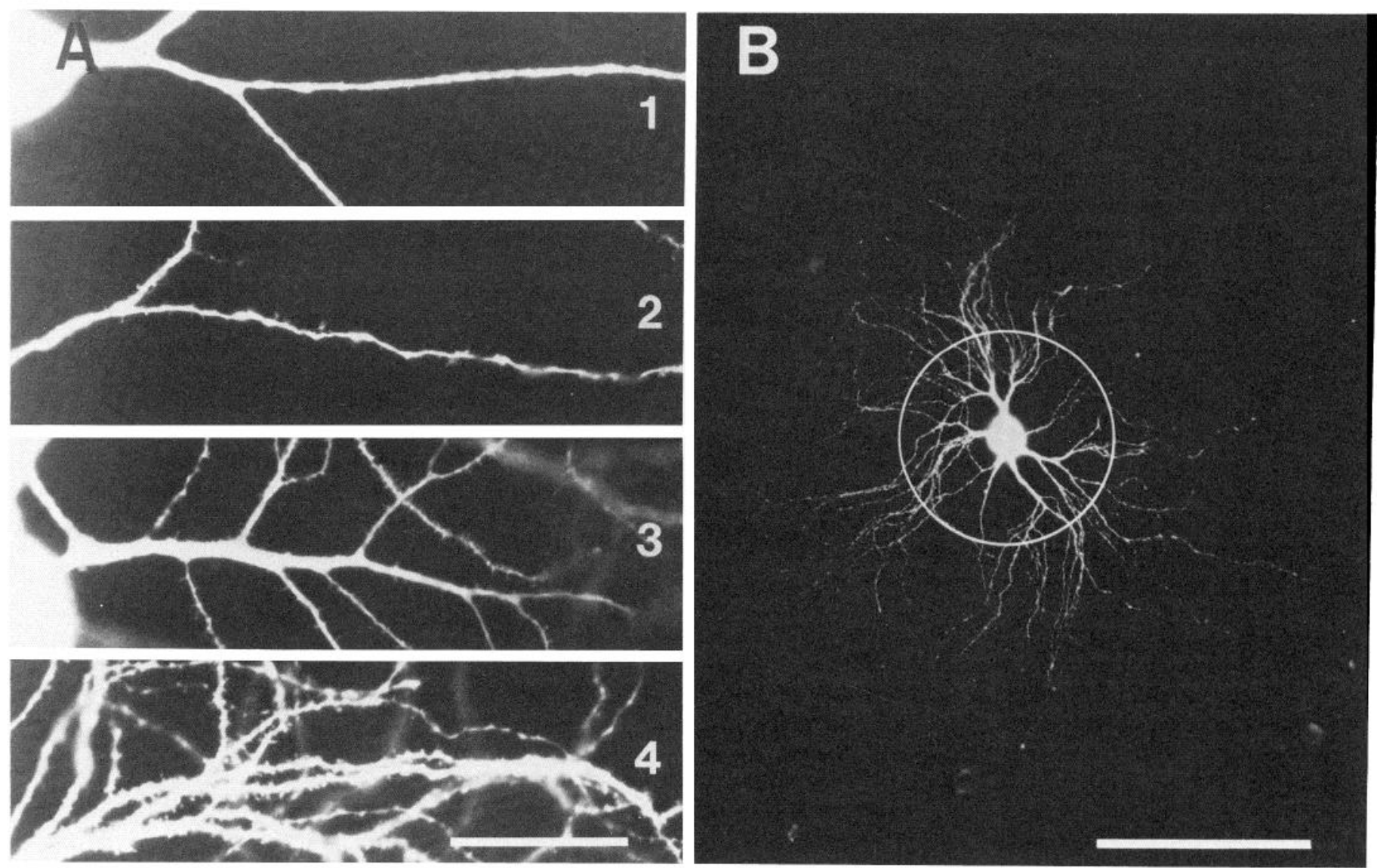

Figure 4. A, Spine index was determined by counting the number of spines visible per $50-\mu$ length of dendrite at a distance of two cell diameters from the perikaryon. 1 to 4 are examples of dendrites classified as nonspiny, sparsely spiny, spiny, and very spiny, respectively. Scale bar $=50 \mu$. B. An index of dendritic branching was obtained by counting the number of processes crossing a circle with a radius of $100 \mu$ as shown for a multipolar neuron with a dendritic index of 50 in this example. Scale bar $=200 \mu$. 

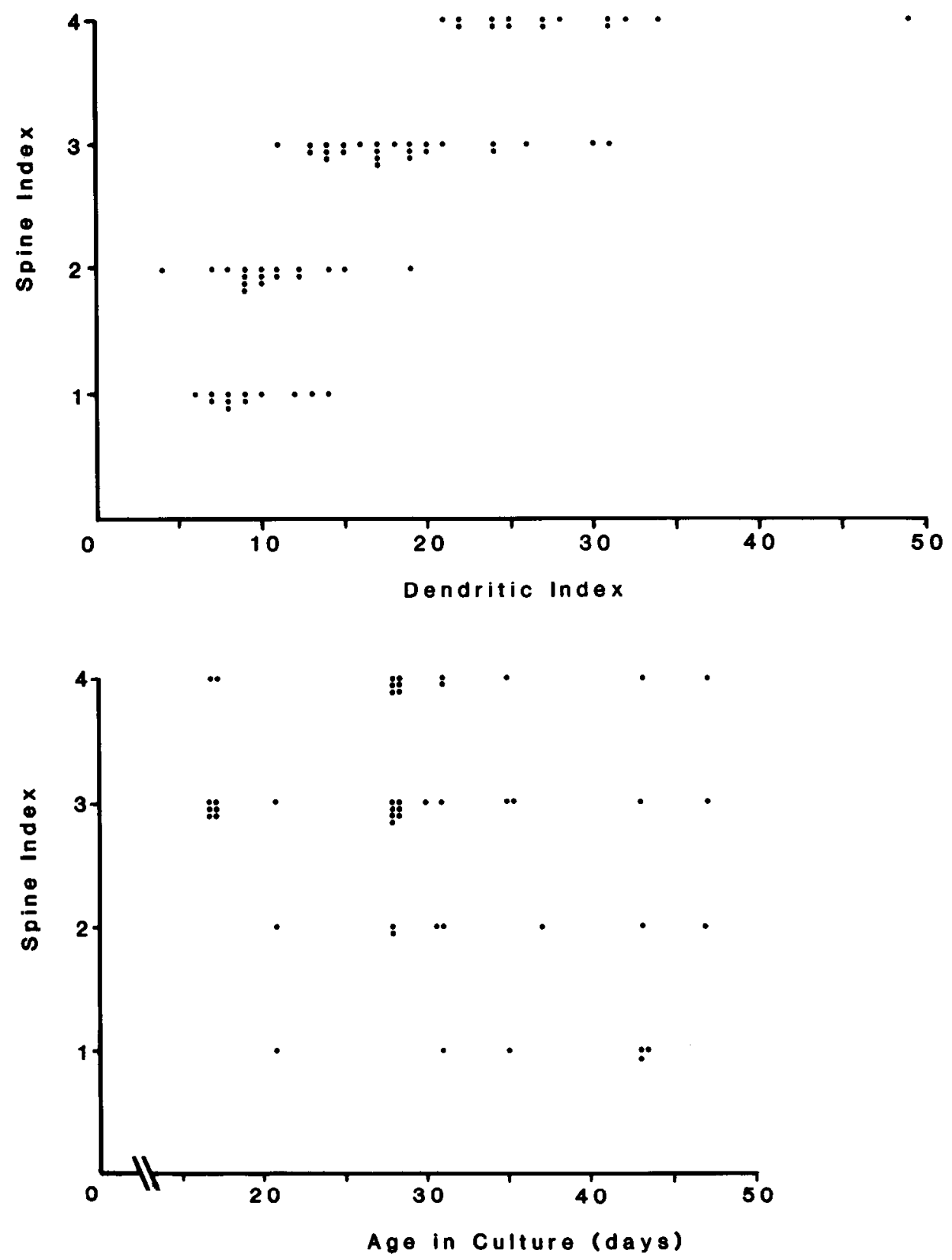

Figure 5. Relationship of spine index to dendritic index and age in culture. The top graph illustrates a correlation between spine density and degree of dendritic branching. Thd bottom graph reveals no clear correlation between spine density and age in culture from 2 to 6 weeks.

illustrates multipolar neurons growing in moderately populated regions of a culture dish. Some neurons developed multiply branching spiny processes (Fig. 7, C and $D$ ) whereas others growing in similarly populated areas of the same dish developed sparsely spined processes (Fig. 7, $A$ and $B$ ). Because cell clusters often formed as cultures matured, it was possible to study single cells with processes that were growing into regions of high cell density and compare them to other processes of the same cell growing into areas devoid of neuron cell bodies. In all cases studied ( $n=8)$, processes of a given cell had an equal spine density regardless of the proximity of other neurons (see Fig. 8). We do not know whether the number of synaptic contacts differs in different regions of the dish, and this may influence the number of spines we observe.

Cell cultures. When cell cultures matured, clusters of neurons would sometimes form and in many cases bundles of fibers would connect one cluster to another nearby. When cells within cell clusters were filled with dye, their processes were often seen to ramify entirely within the cluster or to travel from cluster to cluster along the large neurite bundles (Fig. 9). These cells could not be visualized well enough to categorize.

Axons. Axons were easily identified because they were the finest and longest of the cell processes and were 

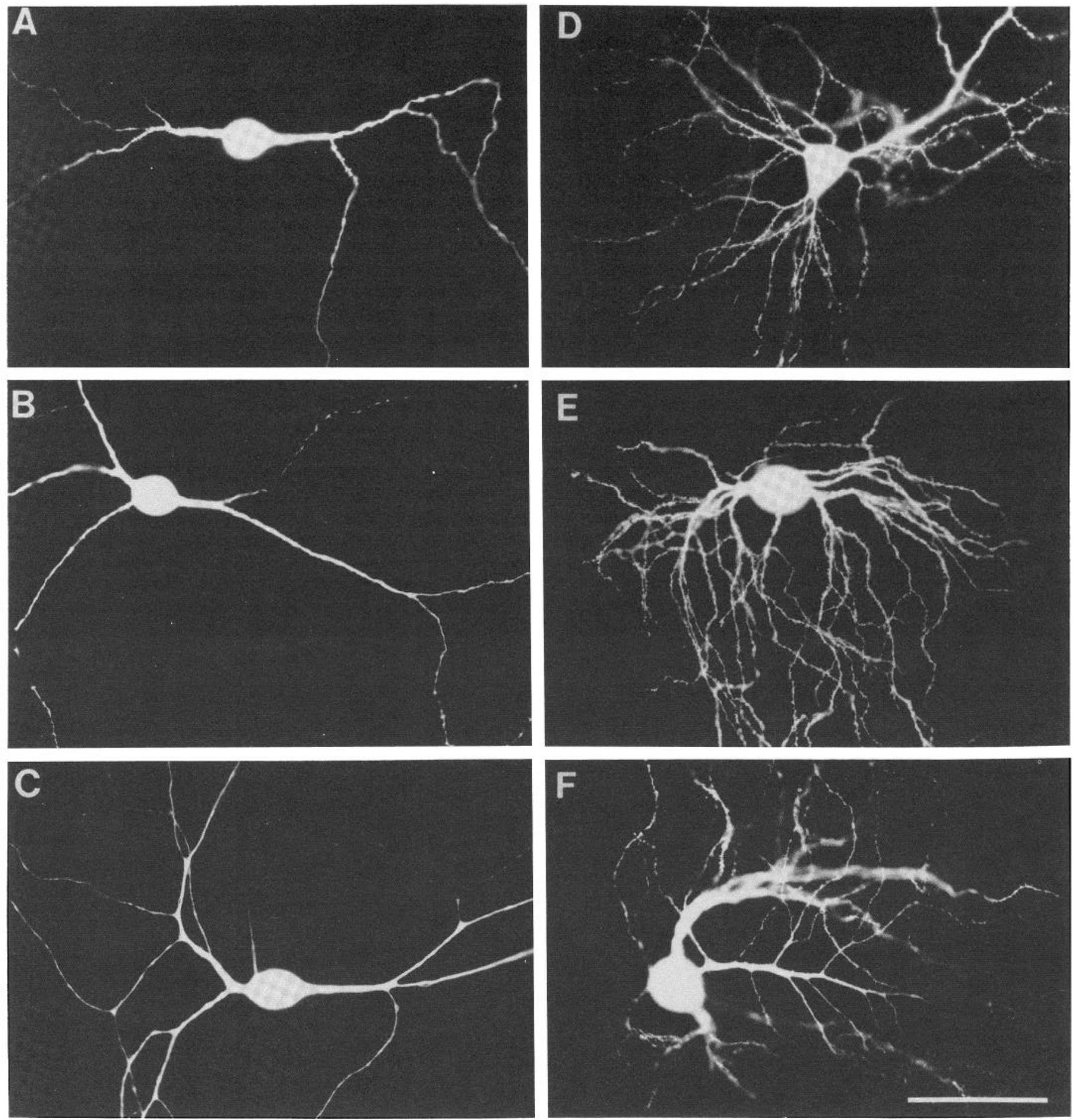

Figure 6. Correlation between cell type and spine density. A, A bipolar neuron with few dendritic branches and few dendritic spines. $B$ and $C$, Fusiform cells with few dendritic branches and no dendritic spines. $D$, A pyramidal neuron with very spiny dendrities. $E$ and $F$, Two multipolar stellate cells with many dendritic branches bearing many spines. All of these neurons were cultured for 4 to 5 weeks prior to filling with dye. Scale bar $=100 \mu$.

totally devoid of spines. Axons did not usually fill completely but became gradually fainter with distance from the perikaryon until they were unresolvable. However, in many cases, at least the initial course of the axon could be determined. Axons most often originated from the cell body near the site of origin of a dendritic process or as a branch off the proximal segment of a dendrite.
Multiple axons were not observed, nor did they arise from terminal dendrites as reported in dissociated hippocampal cultures (Banker and Cowan, 1979). The axons did not usually extend toward nearby cells nor were they clearly oriented toward neighboring cell clusters and often took a relatively straight course running between neuron cell bodies. 

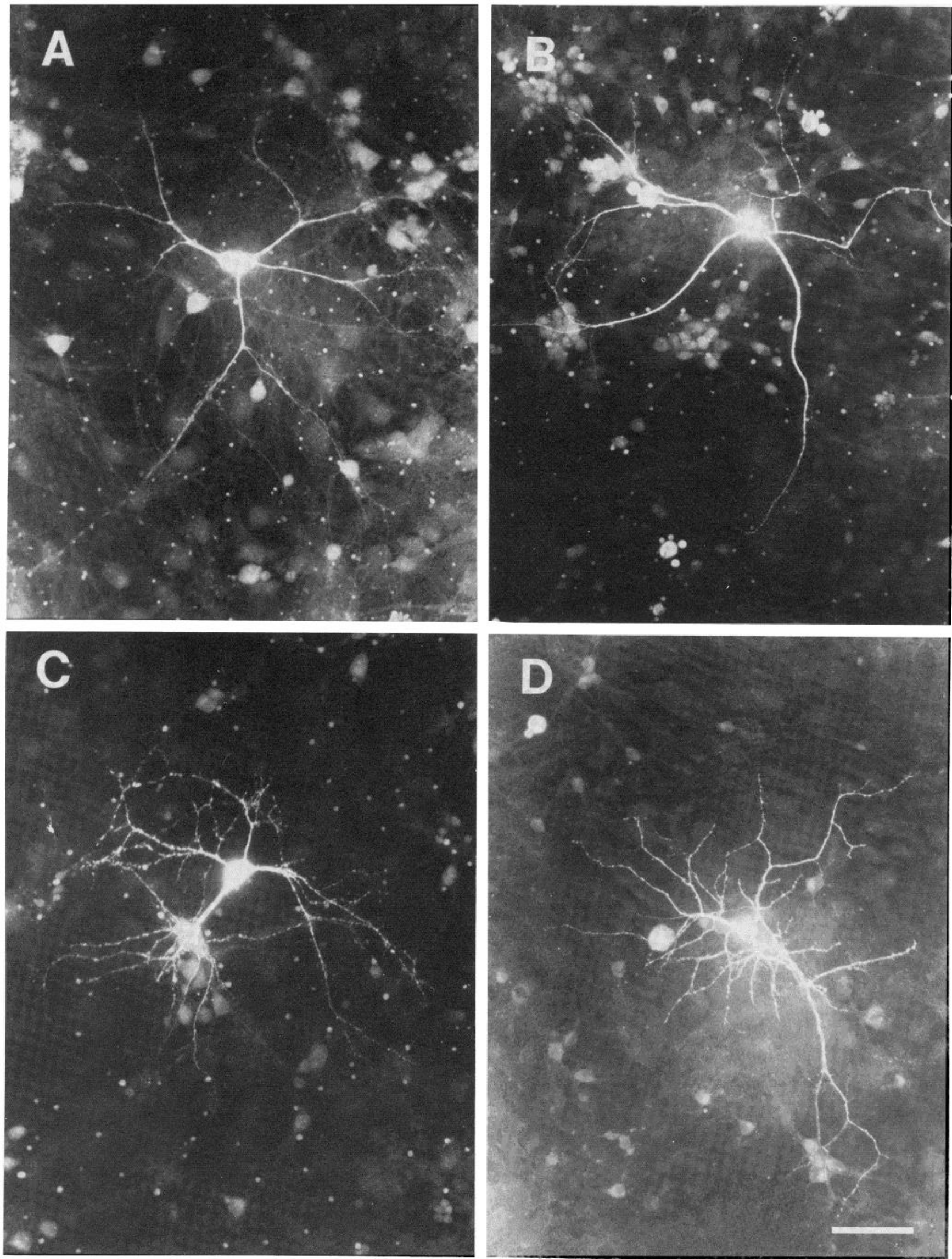

Figure 7. Relationship between cellular density in the environment and spine density. $A$ and $B$, Examples of multipolar sparsely spined neurons growing in moderately populated regions of the culture dish. $C$ and $D$, Examples of multipolar spiny neurons growing in areas of the same culture dish with similar or slightly less surrounding cell density. The brightest cell in each photograph is filled with dye. The remainder of the neurons are visible due to tissue autofluorescence that developed after several months in glycerol wet mounting medium. Scale bar $=100 \mu$. 

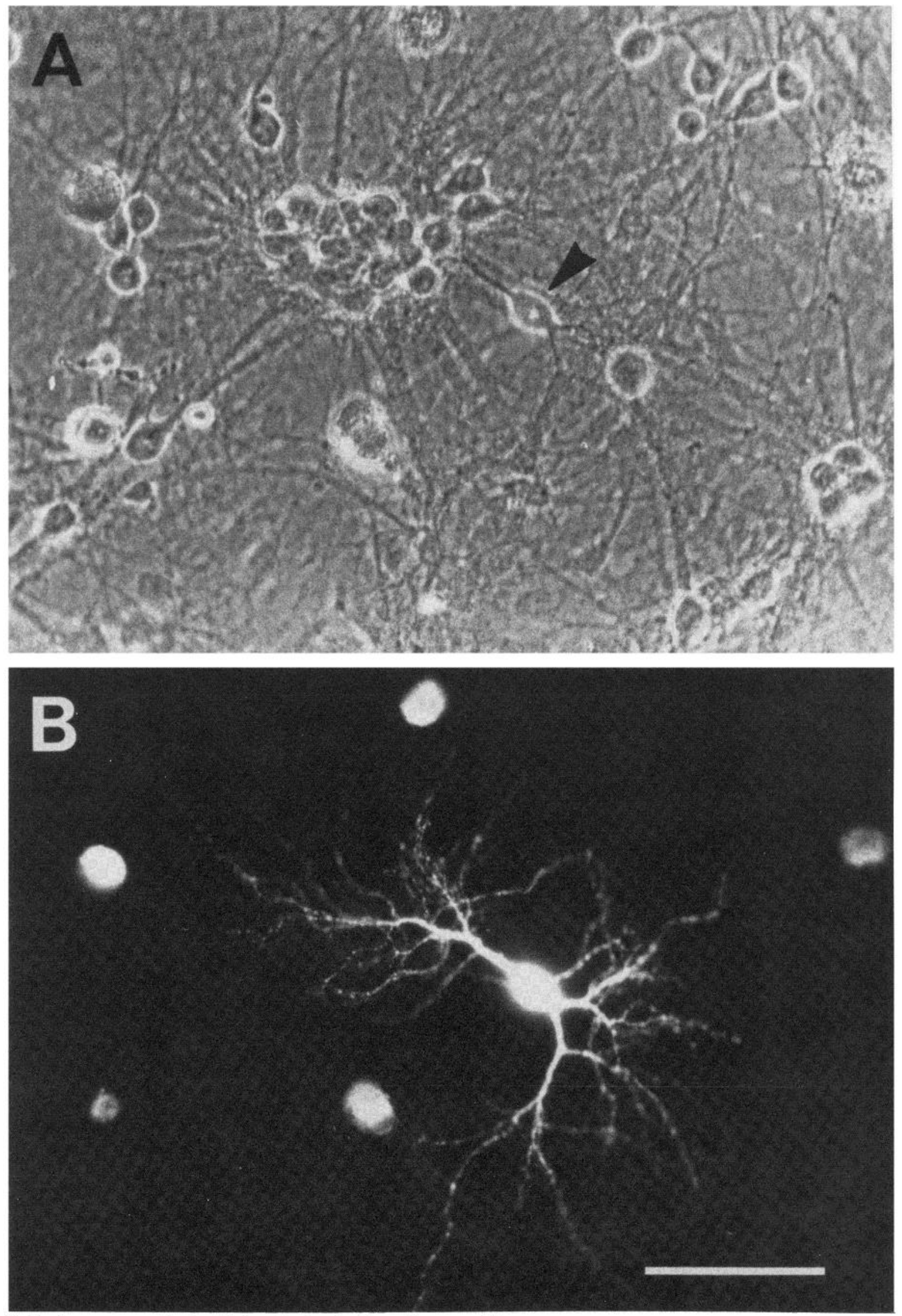

Figure 8. Single neuron with dendritic arborization in a cluster and in a sparsely populated region of the culture. $A$ is a phase contrast photomicrograph with a labeled neuron (arrowhead) near a cell cluster. B, Fluorescent micrograph of the same field as in $A$. This cell has a similar degree of spine density on tertiary dendrites within a cell cluster (mean of 13 spines/50 $\mu$ ) as on tertiary dendrites extending into a relatively acellular area (mean of 12 spines/50 $\mu$ ). Spine counts were obtained at higher magnification. Scale bar $=100 \mu$. 

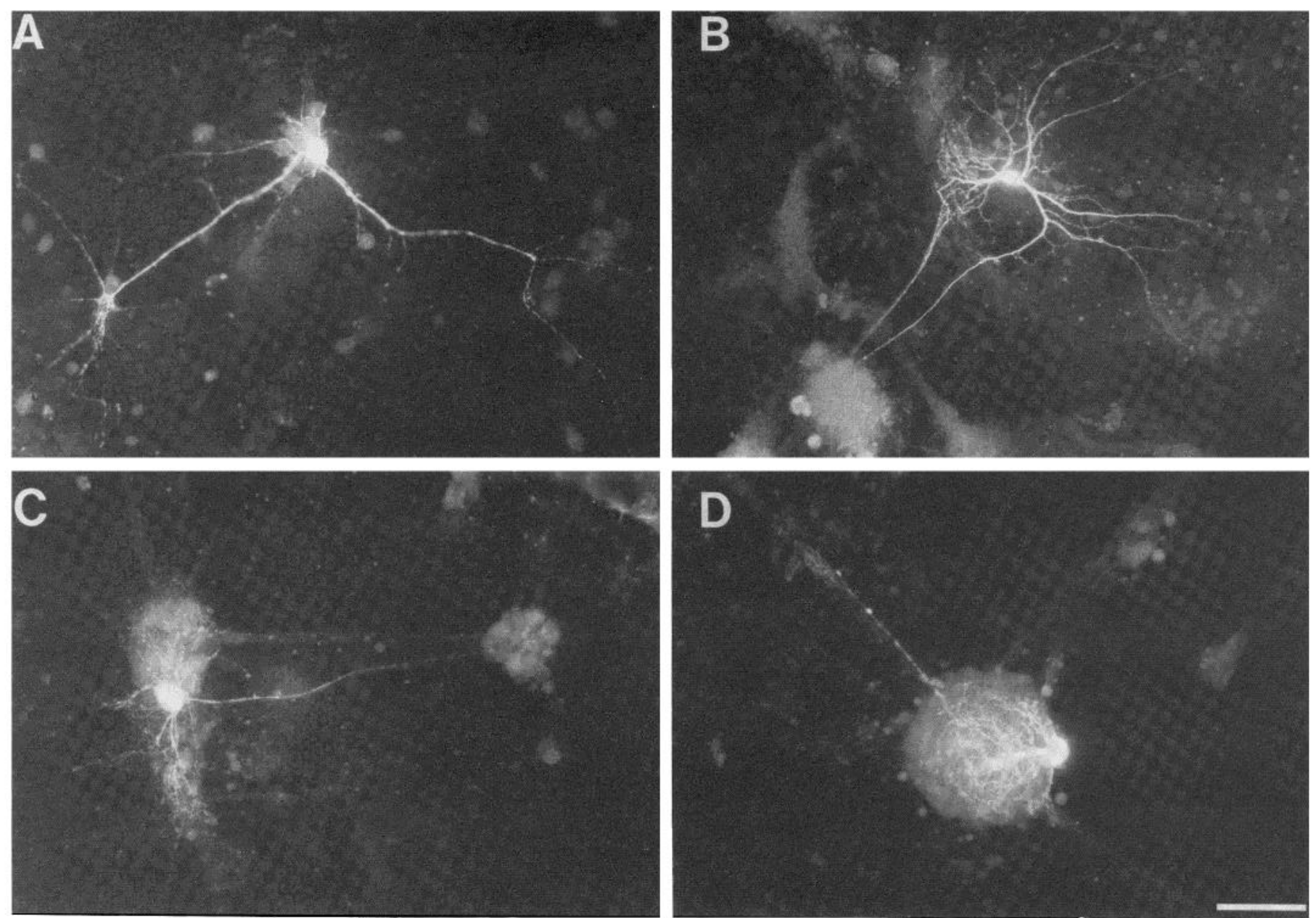

Figure 9. Examples of dye-filled cells that have developed in relation to cell clusters. These cells generally have processes that ramify within the same cell cluster or in adjacent cell clusters. Scale bar $=100 \mu$.

Another interesting feature of axon morphology in these cultures was the pattern of branching. Different types of cells appear to have different patterns of axon branching. The most luxuriant recurrent axonal ramifications were seen in relatively large aspinous multipolar neurons $(n=6)$ (see Fig. 10, $C$ and $D$ ). These cells had multiply branching recurrent axon collaterals that ramified within the area of their dendritic fields and had one primary branch that extended much further. In contrast, large, aspinous fusiform cells $(n=4)$ had several long axon branches with relatively little higher-order branching (see, for example, Fig. 10E). Pyramidal cells $(n=4)$ had axons which gave off arcades of collateral branches and were quite different in this respect from the axons of multipolar or fusiform cells (see Fig. 10, $A$ and $B$ ).

Artifact. Because cells were monitored electrophysiologically and visually while they were filling with dye, it was possible to observe morphological changes that accompany cell death. Occasionally a well filled cell was injured during withdrawal of the electrode. Cell processes would suddenly develop varicosities coincident with the loss of the resting potential. The finest dendrites were the most commonly affected, but if the injury was severe, such as a frank rupture of the cell body membrane, then all of the dendrites and the axon would develop varicosities in seconds (Fig. 11). It is possible that beaded processes observed in some neurons stained by rapid Golgi and Golgi-Kopsch methods also represent a similar response to injury (Garey, 1971; Valverde, 1971; LeVay, 1973; Lund, 1973).

\section{Discussion}

An important question in the study of neuron differentiation is how much of a given cell's shape and function is determined genetically or is "context-independent" and how much is determined by interactions with the cellular environment or is "context-dependent." The classification scheme proposed here relies heavily on the number and distribution of initial processes around the perikaryon to distinguish bitufted cells from multipolar or pyramidal neurons. These features, the number and arrangement of processes about the cell body, are likely to be context-independent properties of cell morphology that can be preserved during in vitro development. Even in neuroblastoma cell cultures where cell shape is highly variable, the morphologies of mitotically related cells are strikingly similar in neurite number, position, length, and branching pattern (Solomon, 1981). Observations of cortical pyramidal neurons in situ support the suggestion 
A

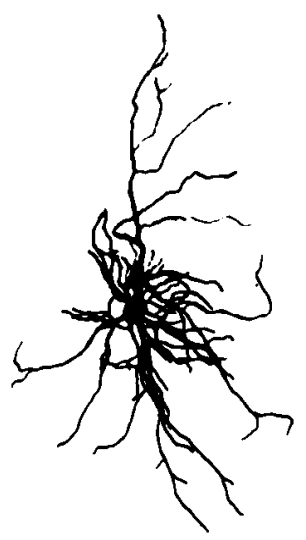

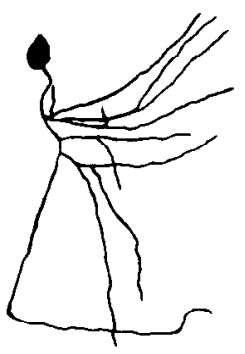

B
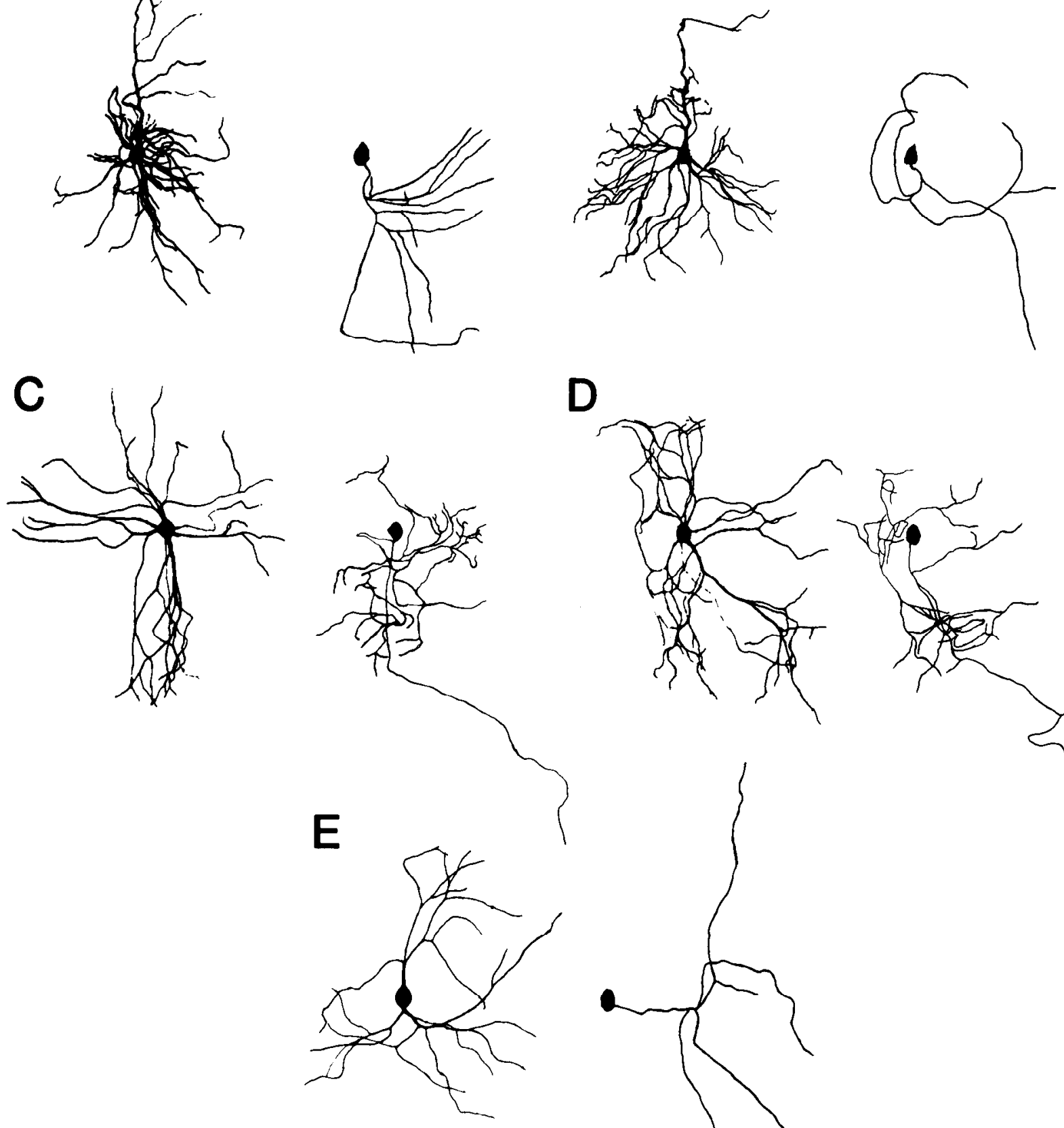

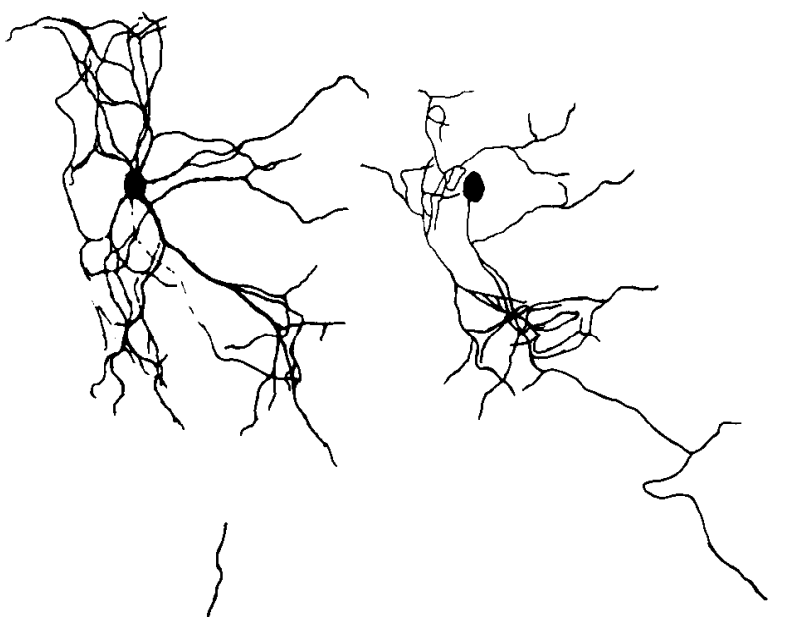

Figure 10. Relation of axon branching patterns to cell type. Reverse-printed photographs of Lucifer Ycllow-filled cells are shown on the left; only the axons and perikarya shown as camera lucida drawings are displayed to the right. $A$ and $B$, Examples of pyramidal-type cells with axons that have arcades of collateral branches. $C$ and $D$, Examples of large multipolar cells with axon branches ramifying within the dendritic field. $E$, An example of a large aspinous fusiform cell with a long, relatively unbranched axons. Scale bar $=100 \mu$.

that the initial direction of outgrowth of axon and dendrite is an intrinsic property of the individual neuron. A small percentage of pyramidal cells in mammalian cerebral cortex are improperly aligned or inverted. In these cases the pattern of dendritic branching and the direction of initial axon growth conform with the axis of the cell body rather than with the orientation of the surrounding cortex (Jacobson, 1978, p. 201). 
There are many reports indicating that environment can influence dendritic branching and spine density. For example, surgical and behavioral manipulations can alter the degree of dendritic branching and the spine density along dendrites of cortical pyramidal neurons. Light deprivation has been shown to decrease dendritic branching in pyramidal neurons in cat visual cortex (Coleman and Riesen, 1968) and also to decrease the number of spines developing on pyramidal cells in the visual cortex of mice (Ruiz-Marcos and Valverde, 1969). Conversely, rearing rats in visually enriched environments has been reported to increase the number of higher order dendritic branches in visual cortical neurons (Volkmar and Greenaugh, 1972) and also to increase the density of spines (Schapiro and Vukovich, 1970; Globus et al., 1973). The number of spines surviving until maturity depends on the development and maintenance of afferent fibers from the lateral geniculate. When lateral geniculate neurons degenerate following enucleation, the spine density of pyramidal cells in the striate cortex decreases (Globus and Scheibel, 1966, 1967a, b, c, d; Valverde, 1968; Valverde and Este'ban, 1968). In addition to the examples already mentioned concerning visual cortex, experimenters using direct electrical stimulation of the neocortex of adult cats reported a subsequent increase in both spine density and dendritic branching in pyramidal neurons (Rutledge et al., 1974).
Many manipulations that alter spine density in vivo, therefore, also have a similar effect on dendritic branching. As shown in this report in Figure 5 (top) the density of spines correlated with the degree of dendritic branching for most neocortical neurons in vitro. It is possible that these two morphological features of neocortical neurons, spine density and dendritic branching, are context dependent, that is, influenced by the same or similar environmental factors, perhaps the number of synaptic contacts or cell-substrate adhesion. We were unable to examine whether the number of synaptic contacts onto a cell influenced its morphology, but we did observe that neuron density in the immediate environment of the cell had no effect. Neurons were observed with equally lush dendritic branches and spines in relatively neuron-sparse areas as well as in heavily populated regions of the dish. This agrees with the observation that hippocampal pyramidal cells develop a similar degree of dendritic branching when grown in high density or low density cell culture (Banker and Cowan, 1979).

Spine density may be context dependent, but the presence or absence of spines appears to be an intrinsic property of a given cell. Globus and Scheibel (1967c) studied rabbit visual cortex cells with the rapid Golgi method and concluded that the presence or absence of spines was more likely a function of output than input. They observed that neurons with extracortical axons had

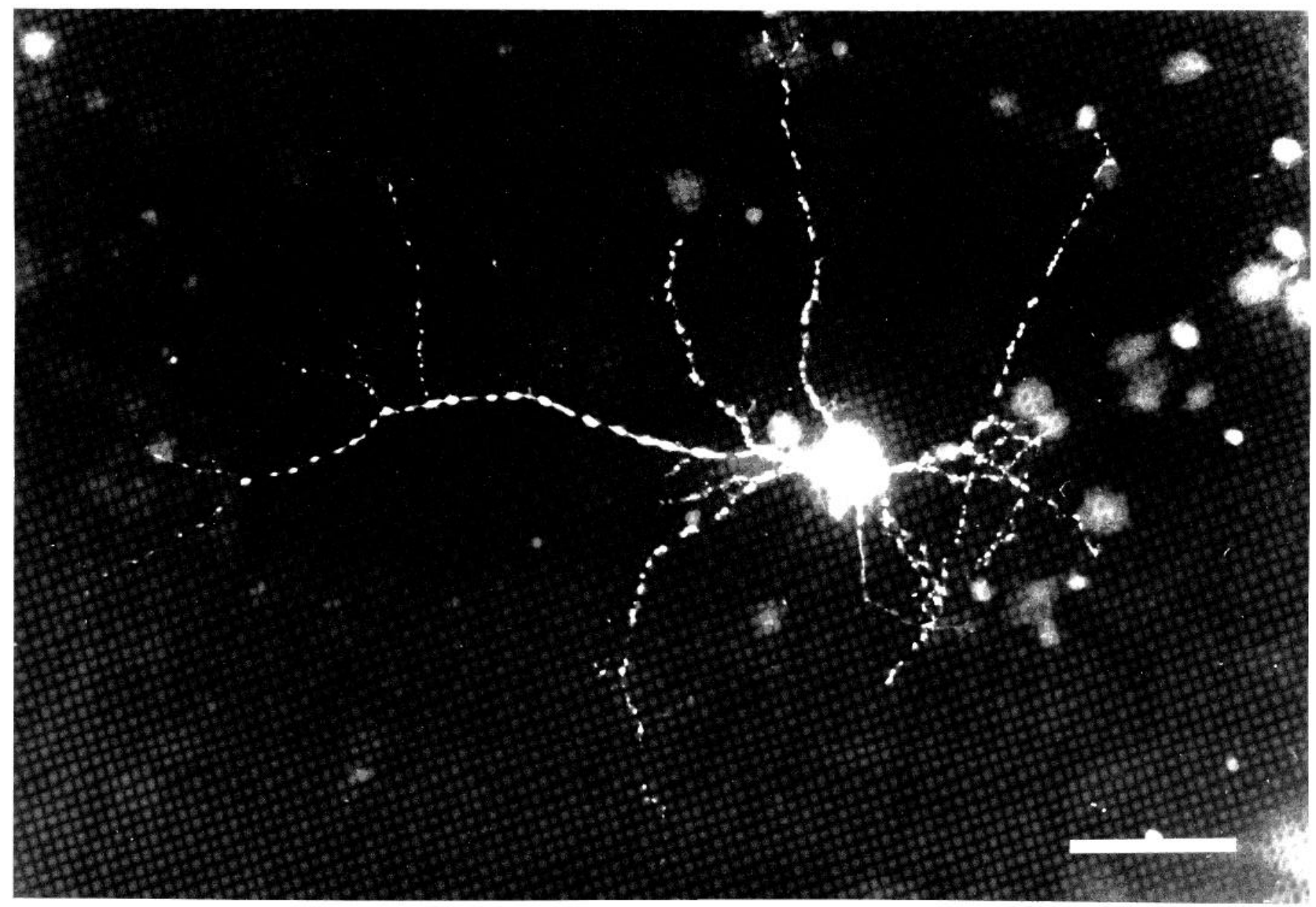

Figure 11. A rapid morphological change associated with injury. A neuron with processes that became beaded over seconds when the cell was injured by a microelectrode after dye filling. Scale bar $=100 \mu$. 
spiny dendrites and cells with intracortical axons were devoid of spines. Similarly, LeVay (1973) also correlated the presence or absence of spines on the dendrites of visual cortical neurons with the morphology of their axons. The presence of spines also correlated better with the cell type than with the environment of the cell in vitro. For example, bipolar and multipolar neurons were the only cells encountered in this study with aspinous dendrites, and pyramidal-type cells always had very spiny dendrites. This suggests that the presence or absence of spines may be an intrinsic feature of the individual neuron and may develop independently of input.

The morphology of neurons grown in dissociated cell culture from a variety of tissue sources has been described, including hippocampus (Banker and Cowan, 1979; Peacock et al., 1979), spinal cord (Neale et al., 1978), and sympathetic ganglia (Landis, 1977; Wakshull et al., 1979). Despite differing culture conditions, all of these neurons develop two types of process, one "dendritic" and one "axonic." Neocortical neurons also develop axon-like processes in vitro. Although it is difficult to examine axonal features in Lucifer-filled cells due to technical limitations (axons do not fill entirely with dye), some were sufficiently well filled for analysis, and, as reported here, the branching pattern of the axons seemed to differ with different cell types. Axon morphology has also been studied in detail in spinal cord cultures (Neale et al., 1978) where excitatory and inhibitory neurons were found to have different characteristic patterns of axon branching. However, axon morphology can be highly pleomorphic in some in vitro systems. Hippocampal neurons in dispersed cell culture may have multiple axons or axons arising directly from dendrites (Banker and Cowan, 1979) and in these respects may differ from hippocampal neurons in vivo.

The orientation of cell processes has been analyzed in terms of the neighboring cellular environment. For example, dendrites or axons might grow preferentially into an area rich in cell processes or in the direction of a neuron cluster or they might preferentially avoid these areas. This study demonstrates that dendrites and axons of some cells differentiate with little regard to the immediate neuronal environment, whereas other cells that form clusters tend to direct their processes toward other cells also in clusters. Another observation was that the axon of a given cell did not usually run in the direction of neighboring cells but most often extended well beyond the closest circle of neurons to distances greater than 200 to $300 \mu$, a distance beyond which dye filling in the slender axons was usually too faint for visualization.

One of the major difficulties in classifying neurons in dissociated cell culture into different morphological types is that cells in culture are removed from the highly organized cortical environment. As a result, cells cannot be classified according to their position or orientation within the cortex. The location of the cell perikaryon within a particular cell layer and the axis of its dendrites or the trajectory of its axon with respect to the pial surface are meaningless features in vitro. However, the classification of cells described here can be compared to the description of neocortical neurons in situ based on Golgi studies if Golgi-stained neurons are removed from their cortical context. The major cell types-pyramidal, fusiform, and multipolar-can be found in vitro as well as in situ. For example, pyramidal cells in vitro can be identified by thick, prominent, apical dendrites even without the presence of a "pial" surface. Moreover, these cell types develop characteristic patterns of dendritic spines and axon morphology. Many of the bipolar and bitufted neurons identified in this study had dendrites that were either devoid of spines or were only sparsely spined. In this regard they resemble bitufted cells described in intact somatosensory cortex (Jones, 1975), visual cortex (Globus and Scheibel, 1967c), and striate cortex (Feldman and Peters, 1978). We propose that these classes of neurons-pyramidal, bitufted, and multipolar-represent distinct cell types that differentiate along different lines even in the relatively unstructured environment of dissociated cell culture. These major morphological features, therefore, appear intrinsic to the development of the cell and may not require a highly organized environment for their expression.

A classification scheme based on morphology is only useful if it can segregate functionally different groups. In this regard, in vitro cell culture offers an opportunity to explore whether the major morphological cell types described here also differ in terms of their physiological and biochemical properties.

\section{References}

Banker, G. A., and W. M. Cowan (1979) Further observations on hippocampal neurons in dispersed cell culture. J. Comp. Neurol. 187: 469-494.

Cajal, R. Y. S. (1911) Histologie du Systeme Nerveux de l'Homme et des Vertebres, Maloine, Paris.

Coleman, P. D., and A. H. Riesen (1968) Environmental effects on cortical dendritic fields. I. Rearing in the dark. J. Anat 102: 363-374.

Dichter, M. A. (1978) Rat cortical neurons in cell culture: Culture methods, cell morphology, electrophysiology, and synapse formation. Brain Res. 149: 279-293.

Difiglia, M., P. Pasik, and T. Pasik (1976) A Golgi study of neuronal types in the neostriatum of monkeys. Brain Res. 114: $245-256$.

Feldman, M. L., and A. Peters (1978) The forms of nonpyramidal neurons in the visual cortex of the rat. J. Comp. Neurol. 179: 761-794.

Fischbach, G. (1970) Synaptic potentials recorded in cell cultures of dissociated nerve and muscle cells in low density cultures. Science 169: 1331-1333.

Garey, L. J. (1971) A light and electron microscopic study of the visual cortex of the rat and monkey. Proc. R. Soc. Lond. Biol. 179: 21-40.

Globus, A., M. R. Rosenzweig, E. L. Bennett, and M. C. Diamond (1973) Effects of differentiated experience on dendritic spine counts in rat cerebral cortex. J. Comp. Physiol. Psychol. 82: 175-181.

Globus, A., and A. Scheibel (1966) The loss of dendrite spines as an index of presynaptic terminal patterns. Nature 212 : $463-465$.

Globus, A., and A. Scheibel (1967a) Synaptic loci of visual cortical neurons of rabbit: Specific afferent radiation. Exp. Neurol. 18: 116-131.

Globus, A., and A. Scheibel (1967b) The effect of visual deprivation on cortical neurons: A Golgi study. Exp. Neurol. 19: $331-345$.

Globus, A., and A. Scheibel (1967c) Pattern and field in cortical 
structure: The rabbit. J. Comp. Neurol. 131: 155-172.

Globus, A., and A. Scheibel (1967d) Synaptic loci on parietal cortical neurons: Termination of corpus callosum fibers. Science 156: 1127-1129.

Golgi, C. (1886) Sulla fina anatomia degli organi centrali del sistema nervosa. Pavia.

Greenough, W. T., and F. R. Volkmar (1973) Pattern of dendritic branching in occipital cortex of rats reared in complex environments. Exp. Neurol. 40: 491-504.

Jacobson, M., ed. (1978) Developmental Neurobiology, Ed. 2, p. 201, Plenum Press, New York.

Jones, E. G. (1975) Varieties and distribution of non-pyramidal cells in the somatic sensory cortex of the squirrel monkey, $\mathrm{J}$. Comp. Neurol. 160: 205-268.

Kelche, C., and B. Will (1982) Effects of postoperative experiments following dorsal hippocampal lesions on dendritic branching and spines in rat occipital cortex. Brain Res. 245: 107-115.

Landis, S. C. (1977) Morphological properties of the dendrites and axons of dissociated rat sympathetic neurons. Soc. Neurosci. Abstr. 3: 525.

LcVay, S. (1973) Synaptic patterns in the visual cortex of the cat and monkey. Microscopy of Golgi preparations. J. Comp. Neurol. 150: 53-86.

Lorente de No, R. (1922) La corteza cerebral del raton (primiera contribucion-la corteza acustica. Trab. Lab. Invest. Biol. Univ. Madr. 20: 47-78.

Lorente de No, R. (1938) The cerebral cortex: Architecture, intracortical connections and motor projections. In Physiology of the Nervous System, J. F. Fulton, ed., pp. 291-325, Oxford University Press, New York.

Lund, J. S. (1973) Organization of neurons in the visual cortex, area 17, of the monkey (Macaca mulatta). J. Comp. Neurol. 147: $455-496$

Neale, E. A., R. L. MacDonald, and P. G. Nelson (1978) Intracellular horseradish peroxidase injection for correlation of light and electron microscopic anatomy with synaptic physiology of cultured mouse spinal cord neurons. Brain Res. 152: 265-282.

Peacock, J. H., D. F. Rush, and L. H. Mathers (1979) Morphology of dissociated hippocampal cultures from fetal mice. Brain Res. 169: 231 246.

Peters, A., and J. Regidor (1982) A reassessment of the forms of nonpyramidal neurons in area 17 of cat visual cortex. J. Comp. Neurol. 203: 685-716.
Ruiz-Marcos, A., and F. Valverde (1969) The temporal evolution of the distribution of dendritic spines on the visual cortex of normal and dark raised mice. Exp. Brain Res. 8. 284-294.

Rutledge, L. T., C. Wright, and J. Duncan (1974) Morphologic changes in pyramidal cells of mammalian neocortex associated with increased use. Exp. Neurol. 44: 209-228.

Schapiro, S., and K. R. Vukovich (1970) Early experience effects upon cortical dendrites: A proposed model for development. Science 167: 292-294.

Scott, B., V. Engelbert, and K. Fisher (1969) Morphological and electrophysiological characteristics of dissociated chick embryonic spinal ganglion cells in culture. Exp. Neurol. 23: 230-248.

Sekuler, M. D., T. Pasik, and P. Pasik (1975) Neuronal types in the monkey neostriatum, Trans. Am. Neurol. Assoc. 100: 239-241.

Sholl, D. A. (1953) Dendrite organization in the neurons of the visual and motor cortices of the cat. J. Anat. (Lond.) 87: 387 406.

Snodgrass, W., F. White, B. Biales, and M. Dichter (1980) Biochemical correlates of GABA function in rat cortical neurons in culture. Brain Res. 190: 123-138.

Soloman, F. (1981) Specification of cell morphology by endogenous determinants. J. Cell Biol. 90: 547-553.

Valverde, F. (1968) Structural changes in the striata of the mouse after enuclcation. Exp. Brain Res. 5: 274-292.

Valverde, F. (1971) Short axon neuronal subsystems in the visual cortex of the monkey. Int. J. Neurosci. 1: 181-197.

Valverde, F., and M. F. Este'ban (1968) Peristriate cortex of mouse: Location and the effects of enucleation on the number of dendritic spines. Brain Res. 9: 145-148.

Volkmar, F. R., and W. T. Greenough (1972) Rearing complexity affects branching of dendrites in visual cortex of the rat Science 176: 1445-1447.

Wakshull, E., M. I. Johnson, and H. Burton (1979) Postnatal rat sympathetic neurons in culture. I. A comparison with embryonic neurons. J. Neurophysiol. 42: 1410-1425.

Waxman, S., M. Dichter, E. Hartwieg, and J. Matheson (1977) Recapitulation of normal neuro-glial relations in dissociated cell cultures of dorsal root ganglia. Brain Res. 122: 344-350.

West, C. D., and T. L. Kemper (1976) The effects of a low protein diet on the anatomical development of the rat brain. Brain Res. 107: 221-237. 